\title{
O DIAGNÓSTICO DE ÉPOCA DE DAVID FOSTER WALLACE: UMA INTRODUÇÃO
}

\author{
ICARO GONÇALEZ FERREIRA ${ }^{1}$
}

\begin{abstract}
Resumo: O objetivo do artigo é constatar e exibir a presença de um diagnóstico de época na obra ensaística de David Foster Wallace, escritor norte-americano, além de indicar suas consequências para a prática literária e suas instâncias políticas. Em suma, esse diagnóstico é constituído por três eixos inter-relacionados - transformações na subjetividade, a ubiquidade de lógica de sedução da qual o modelo narrativo da televisão opera como paradig ma e uma reconceituação da linguagem oriunda da filosofia europeia do século XX. Esse cenário acarreta, de um lado, a necessidade do experimentalismo formal para que o texto literário seja capaz de ressoar a experiência do presente; do outro, uma espécie de rarefação da matéria literária que decorre da textura própria a essa experiência. As mesmas linhas de força que enformam esse cenário são responsáveis pela generalização de processos de terceirização de tomada de decisão, que obrigam a um redimensionamento das noções de cidadania e soberania.
\end{abstract}

Palavras-chave: Pós-modernidade; Literatura americana; David Foster Wallace.

David Foster Wallace (daqui por diante abreviado como D.F.W.), é um dos maiores expoentes da literatura americana do século $\mathrm{XXI}^{2}$. Na medida em que é possível falar em temas centrais num Great American Novel, que almeja ser a apreensão sinóptica da experiência de uma sociedade em uma época, pode-se dizer que em sua obra-prima de 1996, Infinite Jest, eles são as drogas e o entretenimento. Nesse romance, esses dois fenômenos são exibidos ostensivamente como pontos diferentes de um mesmo espectro, ou ainda como diferentes sintomas de certa estrutura subjetiva ou textura cognitiva própria de nosso tempo. A previsão certeira da Netflix ${ }^{\mathrm{TM}}$ na figura da InterLace TelEntertainment ${ }^{\mathrm{TM}^{3}}$ é suficiente para demonstrar a afinação do autor americano com as linhas de força da época. Essa consciência aguda de seu próprio tempo também se faz presente num âmbito menos conhecido da obra de D.F.W.,

\footnotetext{
1 Graduando em Filosofia na Universidade de São Paulo. icaro.fgoncalez@usp.br

2 "Qualquer que seja a opinião sobre a obra de Foster Wallace, é impossível ignorá-la quando se fala da li teratura contemporânea” (PERRONE-MOISÉS, 2016, p. 172).

3 Trata-se de um serviço de streaming de entretenimento de filmes e séries, extremamente popular no universo fictício de Infinite Jest.
} 
sua produção ensaística, constituída por textos como E unibus pluram: Television and U.S. Fiction 4 , Fictional Futures and the Conspicuously Young e Deciderization 2007: a Special Report ${ }^{5}$. Nosso objetivo é delinear os principais traços do diagnóstico de época presente nos textos citados e indicar suas imbricações com as possibilidades e os limites da literatura, além de apontar para suas instâncias políticas.

A constituição desse diagnóstico não se dá em uma área do conhecimento claramente demarcada, perpassando campos como a história da literatura, a filosofia da linguagem, a crítica cultural, sem se fixar em nenhum deles. Sinteticamente, D.F.W. determina a condição contemporânea a partir do entrelaçamento dinâmico de três complexos de fenômenos: transformaçôes na subjetividade, que se revelam de forma mais saliente nos fenômenos do vício e do entretenimento, relacionadas com os mecanismos e a ubiquidade da narrativa televisiva, que por sua vez catalisa e reflete mutações na concepção de linguagem. Essa exposição sintética não jaz jus à forma em que Wallace expõe sua compreensão: através de retomadas, reformulaçôes, modulações de tom e gênero discursivo; tampouco faz jus ao trajeto do nosso esforço de reconstituí-la, composto em sua maior parte por obras autorais em sentido estrito, mas também por entrevistas, correspondência e transcrições de conversaçôes. Visando ser fiel a esses traços, nossa exposição ostensiva se articulará cronologicamente, mostrando as persistências e variaçốes de sua compreensão ao longo do tempo e em meio à multiplicidade de registros discursivos.

Nosso ponto de partida será o ensaio Fictional Futures and the Conspicuously Young, de 1988. O fenômeno que ocasiona o esforço de reflexão registrado nesse texto é uma rápida virada, de "indulgência crítica condescendente” para "dispensa crítica condescendente” (WALLACE, 2013, p. 39) ${ }^{6}$, na relação entre o establishment literário e os escritores que denomina de Conspicuamente Jovens, no breve intervalo entre 1984 e 1987. O termo engloba autores tais como Bret Easton Ellis (Less than Zero, de 1985), Jay McInerney (Bright Lights, Big

\footnotetext{
4 Publicado originalmente na revista Review of Contemporary Fiction (v. 13, n. 2, p. 151-194,1993).

5 Esses dois últimos recolhidos no livro Both Flesh and Not (Londres, Inglaterra: Penguin Books, 2013).

6 Todas as traduções dos textos de Wallace são de nossa autoria, com exceção da passagem de Graça Infinita, mais abaixo.
} 
City, de 1984), Tama Janowitz (Slaves of New York, de 1986), David Leavitt (The Lost Language of Cranes, de 1986), Susan Minot (Monkeys, de 1986), Pinckney Benedict (Town Smokes, de 1987. Esses autores não serão objetos de nossa análise, mas sim aquilo que segundo D.F.W. perpassa-os e faz deles uma geração: "um novo e singular ambiente no qual e sobre o qual tentamos escrever ficção” (WALLACE, 2013, p. 41). Esse traço unificante é ao mesmo tempo a chave para a relação conturbada desses autores com o establishment literário. Existe uma "cisma entre os jovens escritores e seus críticos mais velhos" (WALLACE, 2013, p. 43), um gap geracional constituído por três elementos, responsáveis pelo ruído na recepção dos Conspicuamente Jovens pelo establishment: a) o impacto da televisão na cultura e literatura americanas; b) os Programas Acadêmicos de Escrita Criativa; c) mudanças na compreensão da natureza da arte literária. Esses três elementos são incontornáveis no esforço de compreensão das “Novas Vozes”, contudo, devido às restrições decorrentes do âmbito deste artigo, além da maior importância do primeiro elemento, que será central em momentos posteriores da obra de Wallace, tendo seu escopo ampliado, ele será o principal alvo de nossa atenção, em suas conexões com o terceiro, excluindo o segundo ${ }^{7}$.

“A geração americana nascida depois de, digamos, 1955 é a primeira para a qual a televisão é algo com o qual se convive, e não apenas se vê” (WALLACE, 2013, p. 42), ela se tornou o próprio “medium do intercâmbio social” (WALLACE, 2013, p. 43). Tal ubiquidade afeta a forma com que os escritores experimentam a vida e expressam essa experiência. Um exemplo bem delimitado dessa mutação é a presença na ficção dos escritores C.J. de descrições de personagens constituídas apenas pela nomeação das marcas de suas roupas. O que escapa aos críticos pré-Cisma que rejeitam esse recurso é que ele não é mera escolha estilística idiossincrática, que ela "faz o serviço", porque "fidelidade a marcas agora é uma sinédoque aceitável de identidade, de caráter” (WALLACE, 2013, p. 43). Esse exemplo particular demonstra que a onipresença da televisão - "e de sua publicidade e da cultura pop que ambas refletem e definem" (WALLACE, 2013, p. 44) - faz com que ela passe a manter "relações complicadas com nossas próprias ideias de mundo e de self” (WALLACE, 2013, p. 46).

$7 \quad$ Outra razão para secundarizar o elemento dos programas de escrita criativa é sua maior pertinência ao ambiente cultural dos Estados Unidos da América, sendo relativamente estranho a outros contextos - embora esse cenário esteja se modificando rapidamente. Sinteticamente, o que está em jogo é que os programas de escrita criativa são danosos na medida em que implementam uma lógica escolar na prática literária: "1) Identifique o que os instrutores querem; e 2) forneça imediatamente” (ibid., pp. 58-9), que acaba por instaurar um girar em falso em torna da reiteração de formas que se tornam protocolares. 
D.F.W. então traça um esboço desse entrelaçamento. Mesmo performando a escrita por horas e horas em suas escrivaninhas, os escritores C.J. continuam a ser membros da grande Audiência, sendo condicionados enquanto tal. Quer dizer,

\begin{abstract}
nós temos uma predileção por estimulação visual, movimento colorido, uma variedade frenética, uma batida para qual podemos dançar. Pode até ser que, através de hiper e atrofia, nossas próprias capacidades mentais sejam diferentes: a amplitude de nossa atenção aumenta na medida em que os períodos de atenção em si diminuem (WALLACE, 2013, p. 46).
\end{abstract}

A mutação na forma da experiência é causa de metamorfoses na expressão. Podese constatar a presença de recursos da narrativa televisiva nas obras desses escritores, tais como

eventos frequentemente refratados através da sensibilidade de mais de um personagem; parágrafos curtos e densos nos quais a coerência é sacrificada pela evocação direta; transiçóes abruptas de cena, local, ponto de vista, ordem temporal e causal; um olho narrativo superficial, objetivo, cinematográfico, em terceira pessoa (WALLACE, 2013., p. 47).

Contudo, para D.F.W., essa contaminação entre narrativa televisa e literária não é livre de problemas, não se trata aqui de uma tentativa de reabilitação da televisão e da cultura pop: ao contrário, sua avaliação é que o saldo final dessas transformações é negativo, de que algo se perdeu. Passaremos a expor os elementos centrais dessa avaliação.

A raison d'être da televisão é conservar o espectador diante de si o máximo de tempo possível. Para realizar esse fim ela mobiliza imensas somas de dinheiro, profissionais das ciências sociais, estatísticos, neurocientistas, técnicas avançadas de recolha de feedback, etc. Todo esse esforço por capturar nossa atenção transforma-a em "uma commodity, uma medida de poder, e nossas escolhas de aplicá-la ou retirá-la carregam para nós um grande peso” (WALLACE, 2013, p. 46). Do alto valor que nossa atenção recebe ao ganhar um preço relativo num mercado concorrencial, derivamos o que "consideramos nosso direito dado por Deus de sermos entretidos - ou, se não entretidos, pelo menos estimulados: o desagradável é perfeitamente OK, desde que fixe" (WALLACE, 2013). Assim, a finalidade da televisão não é "transformar ou iluminar ou expandir ou reorientar - mas meramente e sempre engajar, atrair" (WALLACE, 2013, p. 52). A característica mais sedutora da TV é que ela é capaz de oferecer prazer puro: "você pode descansar enquanto é estimulado. Receber sem dar" (WALLACE, 2013). É a partir desse operador que D.F.W. dividirá a literatura contemporânea em dois campos, o da "ficção lixo" e da "ficção séria": a primeira subscreve integralmente à lógica de sedu- 
ção da TV e, portanto, não pode fazer exigências ao seu leitor. Assim, a ficção lixo é uma $e m u$ lação da arte literária, porque carente de toda "reação intelectual ou espiritual ou artística que tornam o intercurso verbal entre autor e leitor [...] uma empreitada humana valiosa e significativa" (WALLACE, 2013, p. 54).

A preponderância da TV na estruturação de nosso campo de atenção tem outra consequência: a "assistibilidade [watchableness]" se torna a medida de todo valor humano. De outro modo, a televisão ocasiona "um giro na compreensão do Eu, de um personagem num grande drama cujo fim é o significado, para um ator numa grande audição cujo fim é parecer, i.e., ser visto" (WALLACE, 2013, p. 50). Esse é outro ângulo a partir do qual pode-se explicitar a inadequação entre a arte literária e a finalidade da TV: a postura subjetiva correlata a cada uma. É por isso que os autores não devem subscrever integralmente à lógica televisiva, mesmo que, sendo uma das funções da literatura a expressão da experiência de estar vivo, e a televisão estruturando largamente essa experiência, seja justificável e até necessário que os escritores mimetizem técnicas narrativas da TV. De outro modo, a consciência do espectador estruturada enquanto tal tem uma gramática visual, ele se pensa em terceira pessoa, como se visto através das lentes de uma câmera. A obra literária, pelo contrário, é como uma partitura: ela só vem à existência na duração, no devir da consciência do leitor, que tem como horizonte existencial o sentido, o significado?

8 Uma longa entrevista de 1996, que retomaremos mais adiante, testemunha a sobrevivência dessas considerações na compreensão que Wallace tem de sua própria escrita. Sobre o Infinite Jest: "O livro é divertido e razoavelmente divertido de ler. Mas é divertido de ler em parte porque eu quis tentar fazer algo que fosse realmente difícil e avant-garde, mas que fosse divertido o suficiente para forçar o leitor a fazer o trabalho exigido" (LIPSKY, 2010, p. 56. Buscamos preservar a oralidade do texto original). Esse estado de coisas impóe a necessidade de um frágil equilíbrio entre o prazer gerado pelo livro - indispensável para garantir que a leitura não seja abandonada precocemente, devido à dispersão da atenção, a crença num direito de ser entretido, etc. — e as exigências, o es forço, o labor que ela impóe ao leitor. Em outra entrevista, de 1993, que também será resgatada num momento posterior: "tem de haver uma recompensa acessível, para que o leitor não atire o livro na parede" (BURN, 2003, p. 33).

9 "Nós, A audiência, e os indivíduos você aí e eu aqui, perdemos todo sentimento de escatologia e, por tanto, de teleologia, e vivemos em um momento que é paradoxalmente vazio de sentido intrínseco ou fim e quase que literalmente eterno" (ibid., p. 51).

Nesse ponto, gostaríamos de explicar uma das balizas de nossa investigação. Nosso objetivo não é defender uma suposta contribuição absolutamente original de Wallace para a interpretação de nossa época de si mesma. Sobre esse tópico, por exemplo, poderíamos citar Baudrillard: “Já não há esperança para o sentido. E sem dúvida que está bem assim: o sentido é mortal. Mas aquilo sobre o que ele impôs o seu reino efêmero, aquilo que ele pensou liquidar para impor o reino das Luzes, as aparências, essas, são imortais, invulneráveis ao próprio niilismo do sentido ou do não sentido. É aí que começa a sedução" (BAUDRILLARD, 1991, p. 201). Nossa tese é simplesmen te que Wallace se inscreve nesse debate, forjando formas iluminadoras e férteis para abordar as questóes em jogo; 
O diagnóstico de época de David Foster Wallace: uma introdução

As relações tortuosas entre literatura e TV serão retomadas posteriormente, partindo de textos que se localizam num momento mais tardio da obra de D.F.W. Antes, no entanto, queremos trazer à tona um último elemento de Fictional Futures, aquele que diz respeito às mudanças na compreensão da função e das possibilidades da arte narrativa, mais exatamente a certo influxo da filosofia europeia do século XX na literatura americana contemporânea.

\footnotetext{
O clima para a 'próxima' geração de escritores americanos — nós devemos decidir respirá-lo ou morrer - é rodeado por aquilo que parece ser a apreciação muito atrasada das estranhas conquistas de alienígenas como Husserl, Heidegger, Bakhtin, Lacan, Barthes, Poulet, Gadamer, de Man. [...] o artista contemporâneo simplesmente não pode mais bancar considerar o trabalho de críticos ou teóricos ou filósofos - não importa o quão estratosféricos - como divorciados de seus próprias preocupaçôes (WALLACE, 2013., p. 63).
}

Em suma, a boa nova trazida por esses ventos continentais é que a linguagem não é "um meio neutro para a transferência de ${ }^{10}$ do artista para a audiência”, ou ainda, a "promoção da linguagem de espelho para olho, de organikos para orgânica" (WALLACE, 2013, p. 64), que tornou impossível qualquer atitude ingênua diante dela. Esse giro, que a princípio parece ter apenas consequências negativas, "ilusões expostas, assunções reviradas, preconceitos custosamente mantidos desmascarados” (WALLACE, 2013, p. 66), pode ser o antídoto para o sentimento de exaustão que domina a literatura, devido à produtividade do quiasma entre artista, linguagem artística e artefato literário que ele traz à luz.

Recorreremos a um breve excurso desviante da ordem cronológica para explicitar a refração desses ventos continentais na avaliação de D.F.W. das condições e possiblidades da literatura na contemporaneidade. David Lipsky acompanhou Wallace durante cinco dias na turnê de lançamento de Infinite Jest, em 1996, registrando as conversações que manteve com

o que viemos tentando demonstrar através da reconstituição o mais rente possível de seus textos, reduzindo nossas intervenções e reformulaçóes a um grau mínimo.

10 "Escolha Tolstoi, Schopenhauer ou Richards e insira 'sentimento', 'liberdade do fenômeno' ou 'condição mental relevante', respectivamente, no espaço em branco” (WALLACE, 2013, p. 64). 
escritor, publicando-as em 2010 no livro Although of Course You End Up Becoming Yourself. No jantar do dia 03 de maio, eles travam uma discussão sobre o realismo e a experimentação na literatura, na qual Wallace afirma, mobilizando certa concepção da linguagem como forma estruturante da experiência, um dos insumos extraídos dos autores citados:

Existem modos em que coisas experimentais e avant-garde podem capturar e falar sobre a maneira que o mundo é sentido em nossas terminações nervosas, de um jeito que coisas realistas convencionais não podem (LIPSKY, 2010, p. 61).

A estranheza das estruturas e esquisitice das formas da literatura avant-garde são condições para que a narrativa ficcional seja capaz de ressoar a cadência cognitiva do presente, "what it feels like to be alive" (LIPSKY, 2010, p. 63). No compasso da consciência contemporânea, "minha vida e meu self não se parecem em nada com um personagem desenvolvido unificadamente em uma narrativa linear" (LIPSKY, 2010); é possível apreciar a leitura de uma prosa realista tradicional, mas ela não é sentida como verdadeira: ao contrário, "eu a leio como um alívio do que é verdade” (LIPSKY, 2010, p. 62). A importância dessa perda do efeito de veracidade da prosa realista, e a consequente necessidade da experimentação formal, ganham inteligibilidade ao recuperarmos aquilo que D.F.W. considera uma das coisas mágicas que a literatura pode fazer, i.e.,

capturar como o mundo é sentido por nós, de um modo tal que eu penso que um leitor pode dizer "Outra sensibilidade como a minha existe”. Algo é sentido da mesma maneira por mais alguém. Para que então o leitor se sinta menos solitário ${ }^{11}$ (LIPSKY, 2010, p. 63).

A edição do verão de 1993 da revista Review of Contemporary Fiction apresentou um longo ensaio de D.F.W., E unibus pluram: Television and U.S. Fiction, e uma entrevista

11 Na entrevista com Larry McCaffery: "Parte central do propósito da ficção séria é dar para o leitor, que como todo nós está meio que isolado em seu próprio crânio, acesso imaginativo a outros eus. [...] Todos nós so fremos sozinhos no mundo real; empatia verdadeira é impossível. Mas se uma obra de ficção nos permite identificar-nos imaginativamente com a dor do personagem, talvez nós possamos conceber mais facilmente que os outros se identifiquem com a nossa" (BURN, 2003, p. 21-2). Uma tópica central para D.F.W., que cabe indicar embora não possamos explorá-la exaustivamente, é a preocupação com o solipsismo. 
com o autor, conduzida por Larry McCaffery. Nessa entrevista, Wallace afirma que o objetivo do ensaio era tecer um "diagnóstico exaustivo" da relação dos espectadores com a televisão, "essencialmente pueril e dependente, como são todas as relações baseadas na sedução" (BURN, 2003, p. 21). Até aqui, ponto pacífico. A nota que ele almejava introduzir era o reconhecimento de "quão complexas e engenhosas são as seduçôes da TV" (BURN, 2003). D.F.W. afirma ser movido em direção a esse diagnóstico pela superficialidade das críticas padronizadas à televisão dos escritores mais velhos - pré-Cisma geracional. Essas críticas não fazem justiça à "força dominante na consciência das pessoas” (BURN, 2003) que a TV representa. Os jovens escritores devem a si mesmos uma explicação acurada de como ela ganhou essa força.

D.F.W. inicia o E Unibus Pluram com uma descrição do tipo ideal dos escritores. Primeiro, eles são "espectadores natos. Eles são observadores”, já que "situações humanas são seu alimento" (WALLACE, 1993, p. 151). Segundo, e um tanto paradoxalmente, escritores tendem a ser "terrivelmente autoconscientes" (WALLACE, 1993), evitando ao máximo serem observados. Esses dois traços tensionados tornam os escritores especialmente vulneráveis às seduções da televisão, e por duas razóes. Lá fora, na vida real, os seres humanos apresentam-se como uma massa proteica, resistindo a qualquer apreensão sintética. A TV oferece uma "alça sincrética” com a qual agarrar essa multidão polimórfica, ela é uma "janela para a autopercepção nervosa da América" (WALLACE, 1993, p. 152): "se queremos saber o que é a normalidade americana - o que os americanos querem considerar normal - podemos confiar na televisão" (WALLACE, 1993). Talvez mais importante ainda, ela oferece observação de mão única: "Podemos relaxar, inobservados, enquanto encaramos" (WALLACE, 1993); observação que parece um presente divino para aqueles, como os escritores e solitários em geral, que não suportam o fluxo de autoconsciência provocado pela presença de outras pessoas, que declinam dos custos emocionais de intercurso humano real, que "se retiram do estressante pôquer de aparências dos E.U.A.”, mas que ainda assim desejam imagens e cenas.

Contudo, assistir TV não é um substituto adequado para a investigação e observação do drama humano real. Escritores são voyeurs, "eles precisam desse roubo visual direto que é assistir alguém, sem que esse alguém prepare um self especialmente assistível [watchable]" (WALLACE, 1993, p. 153). A televisão oferece um falso voyeurismo: "aquilo no qual os jovens escritores vasculham em busca de dados para transformar em ficção já é composto por personagens fictícios em narrativas altamente ritualizadas" (WALLACE, 1993). Claro que todos sabemos disso, mas, enquanto membros da grande Audiência, suspendemos esse saber, 
por seis horas diárias ${ }^{12}$. O que nos torna dispostos a arcar com doses tão cavalares de autoengano? Há vários elementos envolvidos, entre eles a passagem da experiência da vida social como "uma comunidade de relaçôes para uma rede de estranhos conectados por auto-interesse e competição e imagem" (WALLACE, 1993, p. 154), que torna os sentimentos de familiaridade e intimidade propiciados pelos personagens na TV especialmente irresistíveis. Mas o núcleo da sedução da televisão é que "os performers atrás das duas camadas de vidro [câmera e tela] são gênios absolutos em parecerem não-vistos [seeming unwatched]" (WALLACE, 1993). Veja, a televisão é especialmente atrativa para o solitário, para aquele que declina dos custos emocionais envolvidos em estar junto de outras pessoas. O solitário, ao estar com outros, experimenta fluxos de autoconsciência, ou ainda, toma consciência de si mesmo enquanto um corpo visto; fluxo e consciência que são insuportáveis, insustentáveis. É esse o canto da sereia, a promessa que carregam os atores, essas "Imagos ambulantes”: a desaparição dessa interioridade, desse desdobramento reflexivo imensamente desconfortável e custoso. Assim, o mais alto ideal, o modelo de comportamento, o júbilo de viver passa a ser a capacidade de agir naturalmente diante do olhar de milhões e milhões, em suportar esse olhar, em ser tão autoconsciente de si mesmo enquanto um corpo visto a ponto de inibir qualquer expressão dessa consciência $^{13}$ (WALLACE, 1993, p. 154). Esse ideal implica uma subjetividade paradoxalmente autocentrada, sedutora e, portanto, servil ${ }^{14}$; subjetividade na qual há um recuo da interiori-

12 D.F.W. irá bater nessa tecla ao longo de todo o ensaio: a média de tempo gasto diante de uma tela por um cidadão americano na década de 90 eram seis horas diárias. Hoje quase já não é mais possível distinguir o tempo longe da tela do tempo diante dela.

13 Aquela que talvez seja umas expressões literárias mais impressionantes dessa intuição, em Graça Infinita: "A tua mãe é dessa nova geração que se move a contrapelo da vida, contra a urdidura e os aparos da vida. Ela até pode ter amado Marlon Brando, Jim, mas ela não o entendeu, e foi isso que deixou ela estragada para as artes de todos os dias como portas de fornos de garagens e o tênis até de baixo-nível de bate-bola de parques-e-praças. Você já viu a tua mãe com uma porta de forno? É um massacre, Jim, é de chorar de ver, e a coitada da boba acha que é um tributo a esse largado encostado que ela amou quando ele passou roncando. Jim, ela nunca intuiu a economia delicada e ardilosa que existe por trás do manuseio entre aspas rude, impensado e desleixado dos obje tos por aquele sujeito. O quanto ele tão nitidamente tinha treinado vezes sem fim aquela reclinação nas pernas traseiras da cadeira. Como ele estudava os objetos com os olhos de um soldador em busca daquelas suturas centrais e mais firmes que quando pressionadas pelo mais porcamontes dos largados ainda aguentam. Ela nunca...nunca viu que Marlon Brando se percebia tão agudamente enquanto corpo que não precisava de modos” (WALLACE, 2014, p. 163).

14 No conto Good old neon, recolhido na coletânea Oblivion: "A minha vida inteira eu tenho sido uma fraude. Eu não estou exagerando. A maior parte de tudo o que eu fiz foi tentar criar certa impressão de mim em outras pessoas" (WALLACE, 2004, p. 141). 
dade, que se espacializa, passando a se orientar para a produção de frames, de instantâneos: o gesto arrebatador, o close, a cena para ser congelada, o anseio de suspender a sucessão.

A televisão instaura um ciclo aditivo maligno, porque ela "oferece a si mesma como um alívio para os próprios problemas que causa” (WALLACE, 1993, p. 163). Exibiremos dois exemplos desses ciclos que se retroalimentam: o da solidão e do tédio. A atração da TV para as pessoas solitárias se dá em sua oferta de uma simulação de intercurso humano sem os custos emocionais que normalmente estariam envolvidos. No entanto,

quanto mais tempo gasto assistindo TV, menos tempo é gasto no mundo humano real, e quanto menos tempo gasto no mundo humano real, mais difícil se torna não se sentir alienado dos humanos reais, solipsista, solitário (WALLACE, 1993, p. 163).

Há também um elemento de sedução da televisão que apela não só para as pessoas solitárias e escritores: sua capacidade de "arejar" a cabeça das preocupaçóes cotidianas, ou melhor, a ilusão de "transcendência da vida diária”, de que "em algum lugar a vida é mais rápida, mais densa, mais interessante, mais...bem, vívida” (WALLACE, 1993, p. 164). Ora, quanto mais tempo se passa diante da TV - e seu propósito fundamental é perpetuar o especta dor nessa posição - mais intensa e justificada se torna a impressão de que a vida é pálida, opaca, esvaziada de acontecimentos; e mais sedutora se torna a vida fluorescente da tela.

As instâncias políticas do diagnóstico de época de D.F.W são explicitadas em $D e$ ciderization 2007 - a special report. Esse texto é o prefácio que Wallace escreveu para a coletânea The best american essays 2007, da qual foi editor-convidado, publicada pela tradicional editora Houghton Mifflin, fundada em 1832, conhecida entre outras razóes precisamente pela série The Best American, que reúne antologias de melhores ensaios, contos, textos científicos, etc., publicadas anualmente. Contudo, ao invés de escrever um prefácio protocolar, onde apresentaria e louvaria de forma estereotipada os ensaios escolhidos, Wallace percebe que sua posição de editor e as relaçóes que mantém com seus leitores são um modelo, como que uma versão em miniatura das configurações assumidas entre poder, informação e cidadania na contemporaneidade. $O$ primeiro passo na exibição dessa cadeia vertiginosa de associações é uma inversão. Usualmente, os leitores tratam antologias como uma caixa de bombons sortidos: 
“Dão uma olhada, separam e escolhem” (WALLACE, 2013, p. 299). A ausência de um comprometimento linear envolve uma ação de triagem por parte do leitor, uma maior liberdade de escolha, "o que tem a ver com tudo aquilo que a América significa” (WALLACE, 2013). A inversão é que, na verdade, "todo o projeto de uma antologia como essa exige um grau de credulidade e submissão por parte do leitor que pode parecer, à primeira vista, quase antiamericano" (WALLACE, 2013, p. 300).

Visaremos escandir o argumento de Wallace que subjaz a essa inversão através daquele que consideramos o par conceitual estruturante de seu texto, i.e., as noções de cidadania informada e de ruído total. Aquela se manifesta em Deciderization 2007 através de um vocabulário deslizante: "Maioridade informada” (WALLACE, 2013, p. 303), "Lidar com informações de maneira competente e adulta" (WALLACE, 2013, p. 301), "Cidadania informada e educada” (WALLACE, 2013, p. 306), "vida adulta informada e livre” (WALLACE, 2013). A multiplicidade de termos que manifestam a mesma noção não é fortuita, sua função é tornar mais palpável o fato da cidadania informada não ser um predicado fixo que se adquira, nem uma tabela de prescrições e restrições, mas sim uma atividade multiforme que não se esgota em nenhuma das configurações que assume.

Constata-se que o Ruído Total e a cidadania informada se relacionam intimamente através de sua estreia simultânea no texto, onde se delineiam por oposição. $\mathrm{O}$ trecho seguinte se insere na descrição que Wallace realiza de sua atividade como editor, que envolveu ler:

\footnotetext{
ensaios sobre tudo de memória, surf e esperanto até infância, mortalidade e Wikipédia, sobre depressão, tradução, vazio, James Brown, Mozart, prisões, árvores, anorgasmia, cor, moradores de rua, perseguição, felação, samambaias, pais, avós, falcoaria, luto, filmes de comédia - uma taxa de consumo que tende a nivelar tudo em uma massa indiferenciada de descrição de alta-qualidade e reflexão incisiva, massa tão entorpecente quanto euforizante, um tipo de Ruído Total que é também o som da nossa cultura E.U.A. agora mesmo, uma cultura e um volume de informação e spin e retórica e contexto que eu sei que não sou o único a achar coisa demais para sequer absorver, quanto mais atribuir sentido ou organizar em qualquer tipo de triagem de saliência ou valor. Tais absorção básica, organização e triagem costumavam ser o que era requerido de um adulto educado, a.k.a. um cidadão informado - pelo menos foi o que me ensinaram (WALLACE, 2013, p. 301).
}

Há uma homologia entre a situação de D.F.W., responsável pela tarefa de escolher os melhores ensaios do ano, e aquela em que todo cidadão se encontra: ambos são atropelados por um tsunami de informação. A pura quantidade, o mero volume disponível afeta direta- 
mente as três subatividades que costumavam constituir a cidadania informada - ou vida adulta educada, etc. Primeiro, impossibilita a absorção. A totalidade de informação disponível é inabarcável, o que implica uma área cada vez maior de ignorância, ou de emissóes do mundo que não sendo convertidas em sinal, permanecem como ruído. Segundo, impossibilita a organização, mesmo da fatia de informação que é possível absorver. Não somos capazes de metabolizar a massa que absorvemos, ou ainda de atribuir-lhe uma forma que lhe dê coerência e consistência; somos incapazes de tecer as informaçóes na malha de uma visão de mundo coerente. Terceiro, impossibilita a triagem da informação: diante do volume monstruoso, é impossível decidir quais informações absorveremos e reteremos, porque a margem de ignorância é sempre grande demais, o juízo se torna a cada vez precário e arriscado. O Ruído Total, “a estática fervilhante de todas as coisas e experiências particulares, a liberdade total de infinitas opções sobre o que escolher, assistir e representar e conectar, e como e porquê, etc.” (WALLACE, 2013, pp. 302-3), gera como epifenômeno a transformação da cidadania informada, ou melhor, ele nos obriga a repensar as ideias que regulam esta atividade. A ironia objetiva é que é este traço de nosso tempo que fomenta a demanda por serviços como o prestado por D.W.F, "isto é, em retorno por um pagamento e vantagens intangíveis, estou agindo como um filtro avaliativo, peneirando um vastíssimo campo de possibilidades até um Melhores manejável e absorvível para seu deleite” (WALLACE, 2013, p. 303). Ele está agindo como um Decididor [Decider]. Wallace extrai essa palavra, nessa acepção, de uma declaração de George W. Bush: "I hear the voices and I read the front page and I hear the speculation. But I'm the decider, I decide what's best”, feita numa coletiva de imprensa em abril de 2006, respondendo à pressão para demitir o secretário de defesa Donald Rumsfeld, figura proeminente na Guerra do Iraque (2003-2011) e Segunda Guerra do Afeganistão (2001-presente). Nessa torção semântica realizada pelo presidente de seu país, ao utilizar a palavra decider, correntemente utilizada para se referir ao jogo decisivo de uma competição, para se referir a si mesmo, deslocando seu senti$\mathrm{do}^{15}$, D.F.W. vê a chave que abre uma vasta cadeia de associações, vislumbra a armação de uma época: eis a vertigem condensada na inversão inicial entre liberdade e submissão ${ }^{16}$. A fala que

15 O que justifica nossa escolha em traduzir Decider pelo neologismo Decididor, ao invés do vernacular Decisor: desse modo preservarmos a torção semântica presente no original.

16 "A reeleição de 2004 de modo algum teria acontecido [...] se estivéssemos prestando atenção e lidado com as informações de forma adulta e competente. 'Nós' enquanto política e cultura. A premissa não implica culpa específica de ninguém; ou ainda os problemas aqui são emaranhados e sistêmicos demais para o bom e velho apontar o dedo. Por exemplo, é simplista e errado culpar a mídia com fins lucrativos por, de algum modo, fracassar em tornar claros os riscos morais e práticos em jogar no lixo a Convenção de Genebra. A mídia com fins 
tem o maior poder iluminador, ou conteúdo cognitivo, ou força heurística, é a que se dá a contrapelo da linguagem; assim, Wallace deriva dessa palavra torcida um campo neologístico — decidizando [decidering], decidização [deciderization], diferentes ângulos do mesmo nó.

Quanto maior o volume de informaçóes e dados disponíveis, mais somos obrigados a terceirizar essa tarefa ou ação - a de agir como tecedores de sentido e filtros de valor, que deveria ser nossa enquanto adultos educados ou cidadãos informados - para Decididores profissionais. É objetivamente impossível para um cidadão comum ler toda a não-ficção produzida em seu país em um ano, ou mesmo apenas um gênero de não-ficção, como o ensaio. Então, essa tarefa se transforma numa demanda, que será atendida pela editora de predileção de cada um. A editora, por sua vez, terceiriza em segundo grau essa tarefa para um editor-convidado ${ }^{17}$. O mesmo se passa em qualquer campo do conhecimento e da cultura. Há um número de elos e intermediários cada vez maior entre a área sobre a qual o cidadão efetivamente exerce a crítica - e.g., os ensaios recolhidos na coletânea dos Melhores - e que efetivamente existe - tudo o que foi escrito. A dependência de Decisores que se impóe abala nosso sentimento de autonomia. A definição que Kant deu da menoridade, "a incapacidade de se servir do entendimento sem a orientação de outrem” (KANT, s.d., p. 1.), se tornou determinante em nossa concepção da liberdade ${ }^{18}$, formulável a partir de então justamente como o movimento de saída da menoridade: a conquista da autonomia. Pensar com a própria cabeça, em suma. A dependência de Decisores profissionais mina nossa autonomia e, portanto, nossa liberdade: "Não me é forçoso pensar, quando posso simplesmente pagar; outros empreenderão por mim essa tarefa aborrecida” (KANT, s. d., p. 1). Alastra-se mais e mais o sentimento de que aquilo "que parece ser a realidade que experimentamos e na qual fazemos escolhas é na verdade uma pequena e enviesada seção da realidade pré-selecionada para nós por forças e en tidades obscuras" (WALLACE, 2007, pp. 305-6). Um sentimento que nos angustia, a "penetração [dos sujeitos] por sistemas labirínticos” das quais não se tem notícia, penetração que implica o "deslocamento da autonomia [que recua, ganhando cada vez mais mediaçôes] e a

lucrativos é extraordinariamente afinada com nossos interesses e com a quantidade de detalhes na qual estamos dispostos a prestar atenção" (WALLACE, 2007, p. 10).

17 No caso de D.F.W. há mais um elo, já que ele selecionou de uma amostra de 100 ensaios selecionados previamente por um editor-chefe.

18 No escopo deste trabalho não visamos ao sistema kantiano de fato, que permanece um monumento colossal da história do espírito, dotado de força gravitacional tal que inevitavelmente nos arrastaria consigo, mas a certo kantismo diluído, difuso, sedimentado em nossa compreensão rotineira das coisas, kantismo que é abalado pelos processos em jogo, como queremos tornar crível. 
eliminação de fronteiras domésticas seguras [que se tornam porosas]" (GILLES, 2007, p. 339). A progressiva terceirização da crítica, a distância cada vez maior entre o conhecimento existente e o conhecimento acessível, abala a capacidade da autonomia de regular o que entendemos e almejamos como cidadania informada.

Esse cenário implica a necessidade de uma transformação em nossa compreensão das possibilidades de uma cidadania educada: "Talvez acuidade e gosto na escolha dos Decididores aos quais se submeter agora seja a real medida de uma vida adulta informada” (WALLACE, 2013, p. 305). Essa transformação joga luz sobre dois elementos presente em Deciderization 2007. Primeiro, o esforço quase excruciante de D.F.W. em explicitar seus critérios de seleção, reduzindo ao máximo a opacidade da atividade antientrópica característica do editor convidado, de modo que o leitor tenha a maior liberdade possível em sua submissão, em mais uma ironia objetiva. Claro que no limite último há um resíduo de arbitrariedade que não pode ser eliminado; a transparência total é impossível. Ainda assim, com esse esforço, D.F.W. afasta-se do "canto dogmático" dos Decididores que visam ocultar a si mesmos, escondendo sua própria decidização, apresentando seu produto como se fosse simplesmente a realidade dada. Segundo, essa transformação articula-se com os próprios critérios de seleção de Wallace. Quer dizer, as virtudes e valores privilegiados nos ensaios

\footnotetext{
tem a ver com a maneira com que lidam e respondem ao tsunami de fatos, contextos e perspectivas disponíveis que constituem o Ruído Total. [....] Isto é, eles servem de modelos e guias de como peneirar, abater e organizar vastos e complexos conjuntos de fatos de maneiras significativas - maneiras que geram e iluminam a verdade ao invés de simplesmente adicionar mais ruído à balburdia total (WALLACE, 2013, p. 312).
}

Há uma bela reflexividade em jogo aqui, que reforça a ideia de que a Decidização é uma das notas da batida do relógio do mundo, agora. O Decididor editor convidado decidiu por ensaios que apresentam um trabalho de decidização íntegro, que evitam a seleção demasiadamente enviesada dos fatos em nome de uma agenda prévia. Assim, ao se apresentarem não só como "um quantum de informação", mas também e principalmente como "um vetor de significado", eles se mostram como modelos do que pode ser uma cidadania informada hoje, i.e., "lidar com quantidades massivas e altamente entrópicas de informação e ambiguidade e conflito e fluxo; é constantemente descobrir novas áreas de ignorância e ilusão pessoal”. E, talvez o mais importante, significa precisar de ajuda (WALLACE, 2013, pp. 316-7). 
O presente artigo tem uma tese de fundo: se uma filosofia "é seu tempo apreendido em pensamentos”, Wallace coloca-se numa atitude filosófica ao alimentar a pretensão de oferecer um "diagnóstico compreensivo" de uma época. Além disso, o diagnóstico que emerge de seus textos apresenta uma coerência ao longo do tempo, a persistência de uma constelação de ideias, uma contínua autorremissão, um começar tudo de novo a cada vez, um estar "encerrado em si” (WALLACE, 2013, p. 288) ${ }^{19}$, que são precisamente os traços distintivos da prosa pensativa: o método filosófico "consiste na apresentação repetida da sua forma” (MOLDER, 1995, p. 31), apresentação reiterada que se dá “pela perífrase, pelo 'quer dizer', pelo 'isto é', por 'expliquemos por outras palavras', ou 'dito de outro modo"” (MOLDER, 1995, p. 36). A filiação à tradição do diagnóstico de época e a caracterização da sua prova como pensativa são os dois pontos que demonstram a natureza especulativa da obra não-ficcional de D.F.W.

19 Formulação de Wallace para descrever os contos de Jorge Luis Borges. 
O diagnóstico de época de David Foster Wallace: uma introdução

REFERÊNCIAS BIBLIOGRÁFICAS

BAUDRILLARD. Simulacros e simulação. Tradução de Maria João da Costa Pereira. Lisboa: Relógio d'Água, 1991.

BURN, S. J. Conversations with David Foster Wallace. Oxford, Estados Unidos da América: University Press of Mississippi, 2003.

GILES, P. Sentimental Posthumanism: David Foster Wallace. Twentieth Century Literature, Hempstead, v. 53, n. 3, p. 327-344, 2007.

KANT, I. Resposta à pergunta: “Que éo Iluminismo?”, 1784. Tradução de Artur Morão. Disponível em: http://www.lusosofia.net/textos/kant_o_iluminismo_1784.pdf. Acesso em: 31 mar. 2018.

LIPSKY, D. Although of course you end up becoming yourself: a road trip with David Foster Wallace. Nova Iorque, Estados Unidos da América: Broadway Books, 2010.

PERRONE-MOISÉS, L. Mutações da literatura no século XXI. São Paulo: Companhia das letras, 2016.

MOLDER, M.F. O pensamento morfológico de Goethe. Lisboa, Portugal: Imprensa NacionalCasa da Moeda, 1995.

WALLACE, D. F. E Unibus Pluram: Television and U.S. Fiction. Review of Contemporary Fiction, v. 13, n. 2, p. 151-194,1993.

WALLACE, D. F. Oblivion. Nova Iorque, Estados Unidos da América: Little, Brown and Company, 2004.

WALLACE, D. F. Both Flesh and Not. Londres, Inglaterra: Penguin Books, 2013.

WALLACE, D. F. Graça Infinita. Tradução de Caetano Galindo. São Paulo: Companhia das Letras, 2014. 